\title{
Dimensions of Sustainable Research Collaborations in Philippine Universities
}

\author{
Moises Cansana Torrentira Jr. \\ Department of Public Administration and Community Development \\ College of Development Management, University of Southeastern Philippines \\ Mintal Campus, Tugbok, Davao City 8000
}

Moises Cansana Torrentira Jr. (Corresponding author)

Department of Public Administration and Community Development

College of Development Management, University of Southeastern Philippines

Mintal Campus, Tugbok, Davao City 8000

Received: Mar. 7, 2019 Accepted: Apr. 1, 2019 Online published: Apr. 18, 2019

doi:10.5296/jpag.v9i2.14683 URL: https://doi.org/10.5296/jpag.v9i2.14683

\begin{abstract}
The study was conducted to identify dimensions that sustain research collaborations between universities and industries and government agencies in the Philippines. A total of twenty-five participants including regional directors of national government agencies, local government unit heads, managing heads of business chambers, research heads, deans and presidents and vice-presidents of state universities and colleges in Davao Region, Southeastern Philippines served as key informants. The gathered data was processed using INVIVO qualitative software and thematic content analysis.

The study found out that there is growing evidence that universities, industries, and government agencies increasingly rely on each other to carry out research. When sectors collaborate in research, they effectively contribute to economic growth. Hence, in order to sustain successful research collaborations, the following dimensions were culled out from the study: First, typologies of research collaboration include capability-building, management partnership, institutional partnership, and reinforcement. Second, collaborative governance is necessitated through personal relation, establishing rapport, and transparency. Third, collaborative leadership is strengthened by political leadership, micro-leadership, and leadership by character. Fourth, the collaborative research agenda setting where stakeholders
\end{abstract}


and their thrusts and priorities must be involved should be considered. Fifth, research collaboration is sustained by the university's provision of collaborative research enabling resources. Sixth, the university faculty's motivation fosters collaborative research. And finally, strategic actions were formulated to ensure the sustainability of research collaborations.

The study concluded with the development of a framework showing the dimensions for the sustainability of research collaborations in Philippine universities.

Keywords: dimensions, research collaboration, sustainable, Philippine universities, qualitative study

\section{Introduction}

Collaboration has grown from pure methodology to relevant practice. As a method, collaboration is solely treated as a single intervention to the action process while as a practice, it is considered as a necessary action to complete an intervention. Hence, in the face of globalization, ASEAN Economic Integration, K-12 Program and other trends and challenges in the Philippine educational landscape, collaboration has become an indispensable component of effective partnership for sustainable economic development.

The same is true in the conduct of research among universities in the Philippines. Research can be sustained when there is a collaboration between the university, the industry, and the government agencies. In this case, the university mobilizes its resources to conduct relevant researches which the industry and the government agencies seldom have. They need to capitalize on this by commissioning researches and by providing the infrastructure for research collaboration.

There is growing evidence that specific actors increasingly rely on others to carry out research. According to Edmonson, Valigra, Kenward, Hudson, Belfield, \& Koekkoek (2012), when the university, the industry, and the government agencies work in tandem, they become effective channels for innovation and economic growth. Therefore, research collaboration becomes a sharing of resources to sustain continuous production, access, and utilization of knowledge that has great impacts on peoples' lives.

Stories of university's collaboration with the industry and government agencies are not new. Edmonson et al., (2012) further explained that these collaborations improved Europe and Australia's climate for innovation, increased ICT literacy and transformed teaching and learning. Similarly, in the United States, collaboration enabled young and established faculty from various disciplines to become established leaders in a new cross-disciplinary field. Nezu (2005) added that a number of laws were introduced and amended in Korea, Singapore, India, and Thailand to make way for a broader range of collaboration between universities, industry and the government agencies. Literature also confirmed that many countries all over the world have implemented policies to institutionalize and sustain university, industry and government partnerships. One perfect example is the highlighting of research and development in Europe 2020 Strategy as a major element in the advancement of technology and world-class innovations in the EU Member States. 
But in the Philippines, university and industry and government agencies' interaction is said to be minimal. According to The Global Competitiveness Report (2008), the country ranked 65th (out of 131) in terms of collaboration between universities and businesses. Although efforts to modernize higher education are already in place such as CHED's National Higher Education Reform Act, resources have not been fully mobilized, utilized, and maximized to exploit opportunities for potential research collaborations (Ansell and Gash, 2007). The academic institutions such as state and private universities have yet to revisit their policies and guidelines to advance their resources in crafting relevant, responsive, and sustainable research projects.

Inspired by Etzkowitz and Leydesdorf's (2003) Triple Helix Model which describes the interaction and intensive cooperation between the university, industry and the government, it is, therefore, the earnest task of this study to identify dimensions that can be culled from the experience of key informants. These dimensions, if taken seriously, will help to sustain research collaborations between the university, the industry, and the government agencies. The triple helix model therefore argues that the university needs to be directly linked to the industry in order to maximize the industrialization of knowledge.

\section{Methodology}

This study predominantly worked within a qualitative context as the data gathered were in the form of transcripts, descriptions and document analysis. In the words of Patton (2002), qualitative research attempts to understand the unique interactions in a particular situation. He added that the purpose of understanding is not necessarily to predict what might occur, but rather to understand in depth the characteristics of the situation and the meaning brought by the participants. Following the naturalistic paradigm (Koshy, 2005), the study attempted to get inside individuals and institutions to understand the situations of people and the possibility for research collaborations.

To make a meaningful determination of dimensions for collaborative research, grounded theory (Handcock et al., 2009) was employed as a method of qualitative research. The main feature of grounded theory in this study is the development of dimensions that that correspond to the common experiences of stakeholders involved in the research collaboration. The participants of the study included State Universities and Colleges' key officials and heads particularly; the University Presidents, Vice-Presidents for Academics, Vice-Presidents for Administration, Vice-Presidents for Research, Research Directors, Deans, and Program Heads. On the other hand, the participants who represented the industry and the government agencies included key officials and heads of government line agencies, Regional and Assistant Regional Directors, Local Government Unit officials and heads, and heads and representatives from Mindanao Business Council and Chambers of Commerce. However, the study was limited only in Davao Region, Southeastern Philippines due to the proximity of respondents to the researcher and the presence of five state universities and colleges in the area. Further, the study made use of key informant interview to collect the data. Documentary evidence was taken from existing policies, modules or manuals, and other write-ups that support research collaboration. To make a meaningful interpretation, patterns of themes were 
synthesized through thematic content analysis. Thorough extraction of relevant responses and inputs were undertaken and analyzed using the INVIVO in order to come up with the different dimensions of sustainable research collaboration.

\section{Results and Discussion}

The following are the extracted dimensions of sustainable research collaboration. These dimensions provide the enabling environment to sustain possible research collaborations between the university and the industry and government agencies.

\subsection{Typologies of Research Collaboration}

The following are the major types of research collaborations as described by the informants of the study:

\subsubsection{Capability-Building Partnership}

This emphasized the need for building the capacities of human resources both in the university and in the industry and government agencies through continuous training team up, technical assistance, provision of guidance, support, and direction. It is therefore advantageous to research collaborations when all the concerned stakeholders are given the capability to run the research project

\subsubsection{Management Partnership}

The sustainability of research projects is ensured if it is being managed by both the concerned agencies. As espoused by Dent (2006) partner management really is about relationships. It is about understanding the needs of one's business partners and satisfying those needs to the best of one's ability while building trust between the two parties. Hence, research collaborations become sustainable when both partners are involved in managing them.

\subsubsection{Institutional Partnership}

Public-Private Partnership (PPP) is an innovation to extend the resources of both private and public institutions in the conduct of research. Joint ventures can also strengthen the resources of the university, industry and the government for research collaboration. Winner (2011) provided a good insight on this when he explained that clear decision-making guidelines involve all levels in collaboration. That is, sustaining research collaborations requires participation and involvement of the entire institution rather than just the individuals alone.

\subsubsection{Reinforcement}

To sustain research collaborations, strengthening the other partner and constant dialogue with relevant stakeholders should be reinforced. Sharing of resources has been noted to promote research collaboration. At the same time, stakeholders are involved in crafting and executing research collaborations. The consortium of government line agencies, the university, and the industry also facilitated the conduct of research that resulted in huge impacts in the communities. 


\subsection{Collaborative Governance for Sustainable Research Collaboration}

The study found out that sustainable research projects need to be governed in a collaborative way through the following modalities:

\subsubsection{Personal Relation}

Relationships cannot stand strong if it were not personal in the case of research collaborations. Collaborative governance is inspired by "whom-you-know" kind of personal relationship in order to start the partnership. It is, therefore, easier to engage in a collaborative research project if one can establish personal knowledge of the other partner. Twale (2015) supported this when he elaborated that it is all about trusting who you know and knowing whom to trust. To govern collaboratively demands to invest in social capital to build an enduring personal relationship.

\subsubsection{Establishment of Rapport}

More than developing a personal relationship in order to sustain research collaboration is its mutation called rapport. In addition to having good relations with partners, the collaborative leader makes efforts to build special relationships among the different actors in the group. This is very true to research collaboration for one cannot survive in the process without building rapport with partners through organizational trust. When trust is already built, the collaborators would easily transact with the academe for more research collaboration projects.

\subsubsection{Transparency}

According to Luke (1998), as cited in Morse (2007), successful beginnings usually involve a "safe or neutral space for meetings" and a process that is perceived as being legitimate or transparent, not "driven by hidden agendas." This is a very classic exposition of how collaborative governance must be. Transparency means being true to what agreements have been made in the context of collaboration. Aside from trust, organizational confidence must also be built to attract more collaborators and stakeholders to transact research and extension projects.

\subsection{Collaborative Leadership}

A special type of leadership needs to be practiced in order to sustain the research project. This is called collaborative leadership with the following characteristics:

\subsubsection{Political Leadership}

A political leader is someone that has a voice to command through influence to push through the research collaborations. He uses his own strength or resources to ignite more interests and invite more collaboration to sustain the research projects. He must also maintain control in the duration of research collaboration. He knows how to handle the collaboration from beginning to end. He must be mindful of work and financial plan, ensures bird's eye view, oversees and controls the whole collaboration project. But aside from that, he must be research-oriented. 


\subsubsection{Micro-Leadership}

A micro-leader understands each of the phases of the collaboration process and maintains constant contact with the members of the research collaboration project. Hence, he knows every detail for he is hands-on in the operations. A collaborative leader must lead by friendship and trust. Winner (2011) believed that members of the collaborative venture should respect and trust each other and each other's organizations.

\subsubsection{Leadership as Practiced to Enter into Stakeholders' Varying Contexts}

According to Winner (2011), collaborations are stronger and more sustainable if they don't rely exclusively on one charismatic leader but rather allow all of the members to have leadership opportunities. This can be done through training members on meeting management and facilitation, and then rotating responsibilities to organize and facilitate meetings and distributing leadership responsibilities for individual goals or projects within the collaboration.

\subsubsection{Leadership by Character}

The primacy of character of the person to take the lead in research collaboration is not a simple adoption of whatever is the trend but rather a constant practice of the good. A collaborative leader must maintain consistency in making decisions and knows how to keep track of the organization's mission through systematic planning. Bowning (2011) figured this out by big-picture thinking. This means that a collaborative leader, enlivened by his character, knows system-level planning and thinking, and strategic thinking.

\subsection{Collaborative Research Agenda Setting}

When identifying which research themes to be included, all possible concerned stakeholders must be enjoined. Research collaboration becomes more sustainable if the agenda is set collaboratively as well. The study was able to generate the following dimensions of collaborative research agenda setting.

\subsubsection{Stakeholders' Involvement}

In the selection of the research agenda, stakeholders must be involved. This makes sense because research projects must be relevant and responsive to the needs of the industry and the government. Hence, from inception to implementation, stakeholders must take part so that the agenda is aligned, matched, and harmonized with that of the stakeholder's thrusts. The stakeholders are involved if the setting of agenda follows a multi-sectoral approach to address multi-sectoral levels of needs, thrusts, and priorities of the stakeholders.

\subsubsection{Relevant Research Agenda Selection}

In selecting the research agenda to be prioritized, it is necessary to check the relevance, responsiveness, and viability of the agenda. It is also important to consider if they are matched, aligned, harmonized and anchored on the thrusts and priorities of the stakeholders. According to Wilson (2012), the needs of the business do not align with the mission and strategy of the university. In that case, it is important that the university takes its own step to 
adjust the responsiveness of its research agenda to the thrusts and priorities of various agencies. The agenda should be anchored and matched with national and local agenda to make them relevant to the economy.

\subsection{Collaborative Research-Enabling Resources of the University}

The university is privileged to be provided with all the resources that can facilitate research collaborations. These provisions can be converted into strengths to position itself in research collaborations.

\subsubsection{Resources for Research}

The academic institutions are equipped with qualified and highly-trained researchers. The faculty have undergone rigorous exposure to research given the requirement for advanced studies to get a position in the university. These resources can be considered their collaborative advantage due to the nature of their job in the field of research and extension. Also, the university has is known to have the ability to create a neutral decision. They are not easily swayed by the influence of external stakeholders.

\subsubsection{Research-Enabling Organization}

It is undeniable that the academic institutions have strong research culture given the nature of their business. Bowning (2011) stressed that culture is a hidden power in all organizations and rooted in traditional roles, hierarchies, and systems. Culture is also inextricably linked to business strategy and drives outcomes. Salazar and Acosta (2007) pointed out that indicators of research culture include research agenda, policies, and guidelines on research incentives, services and facilities for research, publications, and research capable faculty.

\subsection{Motivation to Conduct Research Collaboration Projects}

Conducting research projects and collaborations is inspired internally and externally. When we speak of internal motivation, it is driven by the personal passion and longing of the faculty to engage in scholarly research. On the other hand, most motivations would come from external factors which are usually stimulated by rewards and punishment.

\subsubsection{Resource Generation Strategy}

Basically, most research engagements of the university faculty are encouraged by the fact that they are able to generate extra money from them. Monetary incentives can be generated when the faculty can publish his research outputs both in national and international journals and publication. The faculty can also receive an honorarium in the conduct of research. But when the engagement is coming from external funders through partnership, the honorarium is even bigger than that of the university-funded research projects. Finder's fee is also found to be one of the good motivations for bringing in external collaborators or funders into the institution.

\subsubsection{Institutional Policies}

External motivation comes from the mandates stipulated in the policies and guidelines of the 
university. By the year 2017, the impact of the K-12 of the Department of Education to the academe's curricular programming will already be felt. Some faculty would retain their subject loading but most of the faculty from the General Education departments would have fewer subjects. Hence, they have to indulge themselves in research and even extension projects. Likewise, the Strategic Performance Management System and Performance-Based Bonus require that the faculty should engage in research in order to gain higher points for bonus purposes. In terms of career advancement of the faculty, they need to consider the guidelines being stipulated in the National Budget Circular (NBC) for the Promotion of Faculty.

\subsubsection{Passion for Research}

Some faculty would opt to conduct research activities because it is their passion to do so. This case is very exceptional and continues to gain attention from the level of the university. Although very seldom, in reality, this type of faculty is motivated by his inclination and love for research.

\subsubsection{Compensation and College Support}

There are other means of motivating the faculty to be involved. Most of these motivations are stipulated in the manuals of each university. When a faculty receives a Special Order (SO) from the Office of the President, he can be given travel grant for paper presentation and forum participation, provided with research personal insurance in conducting research and extension, granted vacation leave granted to researchers or sometimes given load credits or load release (case to case basis). Another best practice of the university is the annual recognition of excellence in the performance of research and extension for the university. This is an individual award given to those who exerted extraordinary performance of duties for research.

\subsection{Strategic Actions to Sustain Research Collaboration}

The university should strategize actions in order to address the emerging issues that inhibit effective research collaborations with the industry and the government agencies. Key informant interview and desk review data revealed the following actions that the university should consider:

\subsubsection{Maintain Focus by Positioning Technique}

The university should focus on its expertise and niche to avoid competition and duplication of the same research project in the same area. This can be done by clustering the research and even extension projects according to the discipline, commodity, or expertise of the university.

\subsubsection{Develop a System}

In order to address the overlapping projects of the university, a system with a standardized structure of research can be developed. This should be universal that every university should follow in every region. When there is a unified project design for every research activity, it can be assured that the university would have a harmonious relationship in dealing with 
development issues of the region.

\subsubsection{Match Resources through Complementation}

The university must be able to attract effective participation among stakeholders so that the need for reinforcing resources can be discussed. Conceptualization and execution of relevant projects should lead to research and extension projects that are aligned and matched with the agenda of external stakeholders. Hence, for complementation to take place, the university must show itself as matching the demands of the stakeholders to sustain research collaborations.

\subsubsection{Replicate Successful Research Projects}

Mihalic (2004) explained that federal funding agencies have increasingly emphasized the need to implement programs that have demonstrated effectiveness. When we say effective, that also means having the quality to be replicated or duplicated in other areas.

\subsubsection{Ensure Effective Communication}

It has been advocated by Gaillard and Arvantis (2013) that communication is a basis for a strengthened partnership in the field of research infrastructures, leading to economies of scale, encouragement of scientific excellence and higher attractiveness for top researchers from all around the world. Formal communication channels exist so there is a "paper trail" or clear flow of information. At the same time, members establish personal connections so the group is more cohesive and able to function effectively as a team. Thus, research collaborations can be sustained when there is constant communication between the partners. It is also important that the research outputs are published to instill transparency and trust.

\subsubsection{Maximize Resource Mobilization}

Koehn and Obamba (2014) explained that resource mobilization means expansion of relations with the resource providers, and the skills, knowledge, and capacity for proper use of resources not only through the use of money but also through the mobilization of knowledge for human use of skills, equipment, services etc. He also added that resource mobilization includes seeking new sources of resource mobilization as well as correct and maximum use of the available resources.

\subsubsection{Develop a Culture of Research}

In terms of research and extension, culture originates from the university's founders and thus institutions with a long history of research already have an advantage according to Patil (2012). For Junger (2013), research culture may develop when at the level of the individual consideration is given to (a) motivation and incentive, (b) developing the institution's endowment of research skills through recruitment and/or education and training and (c) the parallels between the study of research culture and organizational culture per se.

\subsubsection{Maintain External Support}

Wilson (2012) added that government support in research and innovation is important to the 
nation's economic future. But this can also be extended to private sectors and other stakeholders. In developing the journal for publication of university's research outputs, a multi-sectoral approach should be encouraged. It should be refereed with external stakeholders. A key influencer plan to identify major stakeholders that can mobilize and speed up research collaborations is suggested to be developed. This consists of key people that have the charisma to influence and attract collaboration.

\subsubsection{Execute Public Relations}

Winner (2011) stressed that it is important to establish external communication methods from the collaboration to the broader community. Ideally, this would involve the development of a public communications plan. Sullivan and Skelcher (2002) explained that with proactive public relations, organizations can plan and execute strategies and tactics for research collaboration. Journals and publications should be refereed.

\subsubsection{Establish Track Record}

A track record is about gaining merits based on the successful and best practices maintained by an organization. In the words of Typaldos (2001), it is about recognizing and building status based on the organization's actions. As in the case of research collaborations, the university should present itself as having the track record to invite and attract more partnerships. Maintaining transparency is required to attract external funders. The university should also establish high-end research facilities and infrastructure. The university should also capitalize on the replication of quality research projects. When they are replicated, that means they are successful and effective thus establishing a track record. Another way of building track record is through consistency with Memorandum of Agreement or Understanding and other agreements with stakeholders. Basic to the understanding of establishing track record includes having the ability to deliver quality research and scholarly outputs, ability to meet deadlines timely, strengthened the program offerings through accreditation, provision of merits and qualifications of the university to enter into collaborative activities, and strong research culture.

\subsubsection{Prioritize High-Impact Researches}

According to Wilson (2012), impact measures will have a material influence on the outcome for each university department and therefore for its reputation and funding over the forthcoming years. Thus, the university must capitalize on research projects that can create sensible impacts to beneficiary communities.

\subsubsection{Necessitate Relevance of Research Outputs}

Research outputs must be responsive to current trends and challenges, sensitive to the needs of the time and effective in addressing the needs and issues experienced by the stakeholders. By capitalizing on this, research of the university will be sustained.

\subsubsection{Consider External Funding}

According to Winner (2011), collaboration should be fuelled with adequate and stable 
resources to conduct the activities. Hence, funds coming from external stakeholders contribute to the sustainability of research projects.

\subsection{Framework of Sustainable Research Collaboration}

After a careful analysis of the data collected from key informants, the framework was generated that incorporated the identified dimensions of sustainable research collaborations.

The figure below displays the final framework that is hoped to provide the earnest direction in the framing of policies for sustainable research, development, and extension.

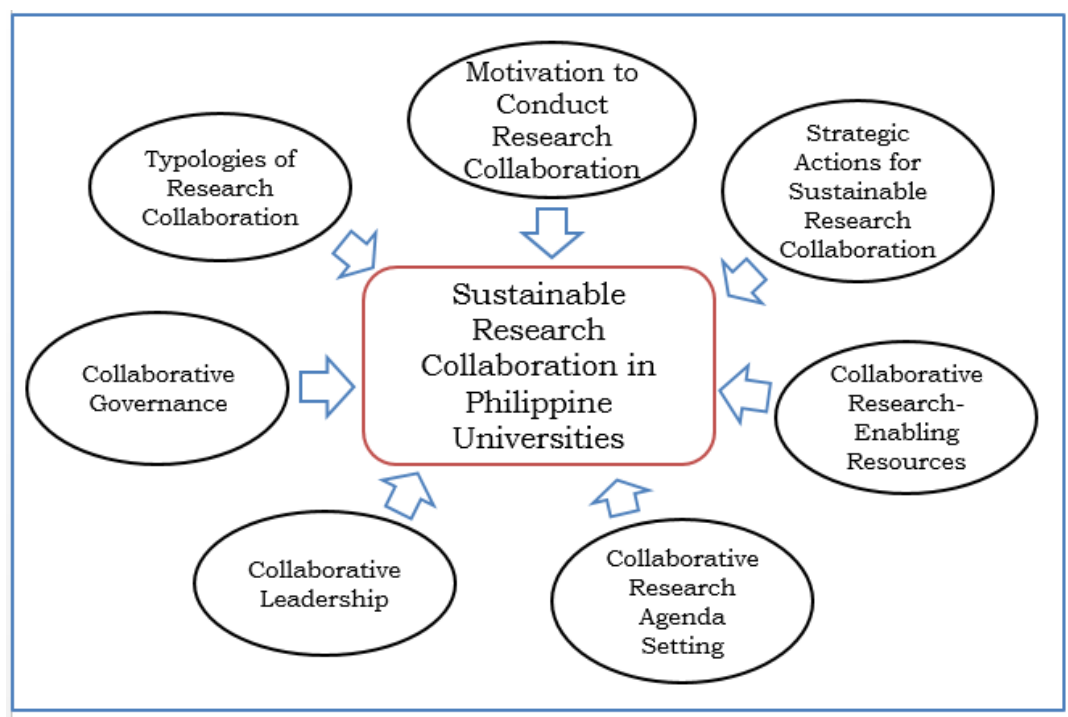

Figure 1. Framework of Sustainable Research Collaborations in Philippine Universities

\section{Conclusion}

Guided by the principles of Triple-Helix Model, the study concluded that research collaboration between the university, the industry, and government agencies is a necessary action if a greater research impact is desired. However, the research collaboration may only be made successfully sustainable if the dimensions found in the framework are seriously considered namely; collaborative governance, collaborative leadership, collaborative research agenda setting, and faculty motivation to engage in research collaborations, collaborative research-enabling resources of the university, and strategic actions to sustain research collaborations. These dimensions will serve as guide for collaborators like managers, teachers, researchers, and government officials and personnel for them to carry out research projects effectively. However, due to some limitations of the study like its area of coverage, it is highly suggested that further research may be made in other regions so as to confirm the dimensions or add more dimensions that may be helpful in the sustainability of research collaborations.

\section{Acknowledgement}

This research was guided by Dr. Rec E. Eguia, a Fulbright-Humphrey fellow. Special thanks to him. 


\section{References}

Ansell, C., \& Gash, A. (2007). Collaborative governance in theory and practice. Journal of public administration research and theory. Oxford University Press. https://doi.org/10.1093/jopart/mum032

Bowning, G. (2011). The collaboration effect: how millennials are impacting leadership. Retrieved from http://www.inc.com/geil-browning/the-collaboration- effect-how- millennialsare-impacting-leadership.html

Dent, H, (2006). Building mutually beneficial school-community relationships. Retrieved from http://www.abcdinstitute.org/docs/Building\%20Mutually\%20 Beneficial\%20School -Community\%20Relationships.pdf

Edmondson, G., Valigra, L., Kenward, M., Hudson, R. L., Belfield, H., \& Koekoek, P. (2012). Making industry-university partnerships work: Lessons for successful collaborations. Brussels, Belgium: Science/Business Innovation Board. Retrieved from http://preserve.lehigh.edu/cgi/viewcontent. cgi?article=1006\&context=fire.

Etzkowitz, H., \& Leydesdorf, L. (2003). Triple helix systems. Retrieved from http://triplehelix.stanford.edu/images/Triple_Helix_Systems.pdf

Gaillard, J., \& Arvantis, R. (2013). Research collaboration between Europe and Latin America: Mapping and understanding partnership. Paris, France: Éditions Des Archives Contemporaines.

Junger, M. (2013). Collaboration between the academic world and industry. Tefen Tribune. Winter Issue. Retrieved from http://www.tefen.com/about_tefen/media_center/tefen_tribune/winter_issue_2013/collaborati on_between_the_academic_world_and_industry.html.

Koehn, P., \& Obamba, M. (2014). The transnationally partnered university. Insights from research and sustainable development collaborations in Africa. New York, NY: Palgrave Macmillan.

Koshy, V. (2005). Action research for improving practice. A practical guide. Thousand Oaks, CA: Sage Publications Inc.

Mihalic, A. (2004). Prevention \& protection brainstorming workshop. Harvard Law School Cambridge, MA. Retrieved from http://www.law.harvard.edu/programs /about/ cap/cap-conferences/pp-workshop/pp-materials/pppacket.pdf

Morse, R. (2007). Developing Public Leaders in an Age of Collaborative Governance. Workshop 4: Leading in a multi-sector environment: University of North Carolina-School of Government, Chapel Hill, NC USA (rmorse@ sog.unc.edu)

Nezu, R. (2005). An overview of university-industry collaborations in Asian countries: Towards effective university-industry partnerships. Retrieved from http://jp.fujitsu.com/ group/fri/downloads/en/economic/20050613WIPO.pdf 
Patil, R. (2012). Academia-indsutry collaboration. Universal Journal of Education and General Studies Col, 1(2), 28-32.

Patton, M. Q. (2015). Qualitative Research and Evaluation Methods. USA: Sage Publications, Inc.

Salazar, \& Acosta. (2007). Developing research culture in Philippine higher education institutions: Perspectives of university faculty Retrieved from http://unesdoc. unesco.org/images/0015/001578/157869e.pdf

Sullivan, H., \& Skelcher, C. (2002). Working across boundaries: Collaboration in public services. Palgrave,

The Global Competitiveness Report 2008-2009. World Economic Forum. Retrieved from http://www3.weforum.org/docs/WEF_GlobalCompetitivenessReport_2008-09.pdf

Twale, D. (2015). A faculty guide to advising and supervising graduate students. New York, NY: Routledge. https://doi.org/10.4324/9781315754727

Typaldos, R. (2001). Cumulative list of organizations described in section one hundred and seventy of the internal revenue code of nineteen hundred and fifty-four. Volume 78 of Publication (United States. Internal Revenue Service).

Wilson, T. (2012). A review of business-university collaboration. Retrieved from https://www.gov.uk/government/uploads/system/uploads/attachment_data/file/32383/12-610wilson-review-business-university-collaboration.pdf

Winner, S. (2011). Building and sustaining effective collaborations. Retrieved from http://alliancefornevadanonprofits.com/wp-content/uploads/2011/09/Research-Brief-Building -and-Sustaining-Collaborations.pdf

\section{Copyright Disclaimer}

Copyright for this article is retained by the author(s), with first publication rights granted to the journal.

This is an open-access article distributed under the terms and conditions of the Creative Commons Attribution license (http://creativecommons.org/licenses/by/4.0/). 